tubing reservoir because they felt that gas was leaking out! As a result the vacuum system built up sufficient negative pressure to hold the diaphragm valve securely on its seating, preventing the escape of any gas. Under these circumstances other designs of scavenge valve permit the high negative pressure to empty the breathing system of gas after which a negative pressure of up to -380 torr can be exerted within the patient's thorax. ${ }^{3}$ The result would be equally lethal. These hazards were pointed out by Sharrock and Leith ${ }^{3}$ in 1977 and were well known to the manufacturer and anaesthesiologist members of the Z79 writing committee who produced the draft standard Z79.11 on Anesthesia Gas Pollution Control. ${ }^{4}$ This standard requires that an interface system with negative and positive pressure limiting valves be provided between the vacuum source and the scavenging valve to prevent such an occurrence.

Unfortunately, like ourselves, most hospitals have the earlier designed equipment which lacks this vital protection. As suitable interface units are now available from most manufacturers which will prevent the development of dangerously high or low pressures within the system, surely we should review the safety of our presently used scavenging apparatus and add negative and positive pressure limiting interface systems?

Leslie Rendell-Baker, M.D.,

Professor of Anesthesiology,

Loma Linda University,

Loma Linda, California 92350, U.S.A.

\section{REFERENCES}

1. Flowerdew, R.M. A hazard of scavenger port design. Can. Anaesth. Soc. J. 28: 481-483 (1981).

2. Miller, M.G. \& Cullen, B.F. The cost of scavenging - Is it worth it? Anesth. Analg. 58: 265-266 (1979).

3. Sharrock, N.E. \& Leith, D.E. Potential pulmonary barotrauma when venting anesthetic gases to suction. Anesthesiology 46: 152-154 (1977).

4. Z79.11.1982 American National Standard for Anesthesia Gas Pollution Control. ANSI, 1430 Broadway, New York, NY 10018.

\section{UNSUSPECTED PHAEOCHROMOCYTOMA}

DEAR SIR,

I am writing to comment on the paper "Unsuspected Phaeochromocytoma Presenting During Surgery" by Doctors L. Wooster and R.I.
Mitchell, which appeared in the September 1981 issue of this journal $(28: 471-474,1981)$.

Several discrepancies are obvious in this paper. The authors stated that "during the procedure the patient's blood pressure rose from $140 / 80$ to $200 / 100$." Figure 1, however, indicates that the blood pressure rose initially to $225 / 230$ systolic. This appears to have occurred 7.5 minutes from the beginning of the anaesthetic. The authors further stated that "Halothane ... was administered to lower the blood pressure towards its preoperative level." Figure 1 indicates that the blood pressure never fell lower than $190 \mathrm{~mm} \mathrm{Hg}$ systolic (much higher than the preoperative pressure of $130 \mathrm{~mm} \mathrm{Hg}$ systolic). Furthermore, "at the end of the procedure ... he was stable at his preoperative haemodynamic values." Again, Figure 1 illustrates that the blood pressure at this time was actually $200 \mathrm{~mm}$ $\mathrm{Hg}$ systolic. One also questions what the diastolic pressures were during the course of this procedure.

The authors also mention that concomitant with the sudden rise in blood pressure, the pulse rose to 130 beats per minute. However, it did not fall below 100 beats per minute during the anaesthetic course. And it was stated that the 45 -minute procedure "was done under general anaesthesia using ... Innovar $2 \mathrm{ml}$." However, only $1 \mathrm{ml}$ appears to have been given according to the Figure.

This paper adequately relates the proper management of a patient who has sustained a myocardial infarction. As the authors stated in their discussion, myocardial infarctions have previously been reported to occur in patients with a phaeochromocytoma undergoing general anaesthesia.

It has been well documented that if a sudden, unexplained, sustained rise in pulse and blood pressure occurs during an anesthetic administration, one should always suspect a phaeochromocytoma. The procedure should then be terminated as quickly as possible, and a cause for this increase by investigated. ${ }^{1,2} \mathrm{As}$ indicated in this paper, this massive rise occurred 7.5 minutes into the anaesthetic. One questions, then, why the procedure was allowed to progress for 37.5 minutes under such unusual circumstances.

The authors do not mention whether this massive elevation of blood pressure and pulse occurred in relationship to any external stimulus such as intubation, surgical incision, too light anaesthesia, or other factors. If the only temporal relationship to the elevation in blood pressure 
was the administration of Innovar (as depicted in the Figure), it has been shown in 15 patients that Innovar (i.e. Droperidol) can precipitate a hypertensive crisis in patients with a phaeochromocytoma. ${ }^{3-5}$ Nitroprusside is a far better agent than halothane to control this massive rise in blood pressure, as halothane may give rise to severe arrhythmias..$^{5-7}$

Pancuronium has also been thought to cause a massive elevation in blood pressure in a patient with a phaeochromocytoma. ${ }^{8}$ However, the patient received $7 \mathrm{mg}$ of pancuronium at the start of the procedure, and the pressure did not rise for 7.5 minutes.

Should hypertension occur after the administration of Innovar (i.e., Droperidol) and the abdomen has not been entered, the procedure should be cancelled and, if necessary, the patient should be given nitroprusside. A thorough work-up for a phaeochromocytoma must commence as soon as the patient's condition is stable. If the abdomen is already open, the patient should first be stabilized with nitroprusside (holding in abeyance any abdominal manipulation) and then the abdominal cavity systematically searched for a phaeochromocytoma. ${ }^{2}$

It would seem that this case report represents another instance where Innovar (ie, Droperidol) has caused a hypertensive crisis in a patient with a phaeochromocytoma. If one chooses to administer Innovar to patients known to have a phaeochromocytoma, it must be used with extreme caution, and any crisis occurring should be treated promptly and appropriately.

David A. Bittar, M.D., Department of Anesthesiology, Lahey Clinic Medical Center.

\section{REFERENCES}

1. Robertson, A.I. Pre- and post-operative care of patients with phaeochromocytomas. Postgrad. Med. J. 41: 481-484 (1965)

2. Flint, L.D. Department of Urology, Lahey Clinic. Personal communication (1981).

3. SumikaYa, K. \& AMAKATA, Y. [Neuroleptanesthesia in pheochromocytoma.] Jpn. J. Anesthesiol. 23: 1242-1248 (1974). English-language abstract.

4. Sumikaya, K. \& AMaKata, Y. The pressor effect of droperidol on a patient with pheochromocytoma. Anesthesiology 46: 359-361 (1977).

5. BITTAR, D.A. Innovar-induced hypertensive crises in patients with pheochromocytoma. Anesthesiology 50: 366-369, (1979).

6. VAN Way, C.W. 3RD, ScotT, H.W. JR, PAge, D.L., et al. Pheochromocytoma. Curr. Probl. Surg, 1-59 (1974).

7. ETSTEN, B.E. \& Shimosato, S. Halothane anesthesia and catecholamine levels in a patient with pheochromocytoma. Anesthesiology 26: 688-691 (1965)

8. JONES, R.M. \& HILL, A.B. Severe hypertension associated with pancuronium in a patient with a phaeochromocytoma. Can. Araesth. Soc. J. 28: 394-396 (1981).

ERRATUM

\title{
MANAGEMENT OF A MALIGNANT HYPERTHERMIA PATIENT DURING CARDIOPULMONARY BYPASS
}

\author{
R.J. Byrick, D.K. Rose and N. Ranganathan
}

Can. Anaesth. Soc. J. 29: 50-54. (January 1982)

Page 54, line 5: "hypothermia" should be "hyperthermia". 